\title{
Marya SCHEChtMAN E Christine KorsGaARD: UMA REFLEXÃO SOBRE UNIDADE FORENSE E SELFMORAL
}

\author{
MARYA SCHECHTMAN AND CHRISTINE KORSGAARD: \\ ON FORENSIC UNITY AND MORAL SELF
}

\author{
ADELINO FERREIRA ${ }^{1}$ \\ Instituto Federal de Educação, Ciência e Tecnologia Baiano - Brasil \\ adefer86@yahoo.com.br
}

\begin{abstract}
RESUMO: O artigo discute o tema da identidade pessoal a partir do debate entre as filósofas Marya Schechtman e Christine Korsgaard. Para isso, será inicialmente explicitada a temática da identidade pessoal em suas origens modernas, nas reflexões lockeanas. O tema da continuidade psicológica na obra de John Locke será brevemente abordado, assim como sua recepção pela obra de Derek Parfit. Sobre o debate específico entre Schechtman e Korsgaard, será apresentada a crítica de Schechtman à noção de independência metafísica do conceito de pessoa e discutido em que ponto isso afeta ou não a posição central de Korsgaard a respeito do tema.
\end{abstract}

PALAVRAS-CHAVE: Identidade pessoal. Self moral. Unidade forense.

ABSTRACT: The article discusses personal identity by Marya Schechtman and Christine Korsgaard. For this, the topic of personal identity in its Lockean origins will be initially explained. The theme of psychological continuity in Locke's work will be briefly discussed and his reception by Derek Parfit. On the Schechtman and Korsgaard debate, it will be presented and discussed the Schechtman's criticism of the Korsgaardian position in favor of the metaphysical independence of the concept of person.

KEYWORDS: Personal identity. Moral self. Forensic unity.

\section{INTRODUÇÃO}

Este artigo trata do tema da identidade pessoal e seus desdobramentos nas questões de responsabilização moral dos agentes. Para isso, serão discutidos criticamente critérios de identificação da pessoalidade e a plausibilidade de se pensar a discussão sem uma carga metafísica robusta. Serão também analisados os conceitos de unidade forense e self moral de modo a compreender de que maneira eles se relacionam e em que medida eles ajudam a compreender a responsabilidade do sujeito no âmbito da ação.

\footnotetext{
${ }^{1}$ Doutorando em Filosofia pela Universidade Federal de Minas Gerais (UFMG). Professor do Instituto Federal de Educação, Ciência e Tecnologia Baiano (IF BAIANO).
} 
De início, busco apresentar as raízes da discussão sobre identidade pessoal em John Locke. A escolha é justificada por ser o Ensaio sobre o Entendimento Humano uma obra canônica sobre o tema, em especial o Livro II. No texto em questão, Locke visa tratar a identidade pessoal sem comprometimentos metafísicos substanciais, diferentemente, por exemplo, do que fizera Descartes em suas Meditações. No capítulo 27 do Ensaio, identidade pessoal é definida nos seguintes termos: "[...] apenas nisso consiste a identidade pessoal, isto é, na mesmidade do ser racional" (LOCKE, 2015, p. 176).

Mesmidade do ser racional significa, para os propósitos de Locke, a extensão da consciência no tempo. Em outras palavras: será o mesmo aquele ente estendido temporalmente, na medida em que é capaz de ser consciente, de alguma maneira, de ações feitas no passado. Como se pode perceber, trata-se de uma maneira muito específica de pensar a questão da identidade pessoal. Isto porque, de saída, exclui a necessidade de um mesmo corpo para a definição da identidade. Locke afirma que, se aquele que estava escrevendo naquele momento tivesse a mesma consciência de que viu o dilúvio, como tinha de que viu o transbordar do Tâmisa no ano anterior, seria a mesma pessoa, o mesmo eu, em todos aqueles momentos (LOCKE, 2015, p. 181). Cabe, pois, destacar uma passagem do texto que é certamente iluminadora: "Isso pode nos mostrar em que a identidade pessoal consiste: não em identidade de substância, mas, como disse, em identidade de consciência, a qual, se é concordante em Sócrates e no atual prefeito de Quinborough, eles são a mesma pessoa" (LOCKE, 2015, p. 182).

A teoria de Locke ficou conhecida como uma teoria da continuidade psicológica. Isso porque, mais do que por um corpo, uma substância ou uma espécie, a identidade pessoal é constituída pela continuidade de eventos psicológicos interligados de forma sucessiva. Contemporaneamente, um célebre seguidor das ideias de Locke foi o filósofo Derek Parfit. Em Reasons and Persons, considerada uma obra inescapável para a compreensão contemporânea do problema da identidade, Parfit desenvolveu uma série de insights presentes no texto lockeano, de forma a responder aos críticos e a esclarecer pontos obscuros do pensamento de Locke. A preocupação com o pensamento de Parfit, neste trabalho, é, contudo, marginal. Algumas de suas teses entrarão aqui apenas como parte do diálogo com as autoras que interessam de modo mais imediato à discussão aqui apresentada.

Uma dessas autoras é Marya Schechtman, em especial, em sua obra Staying Alive. Schechtman defende uma noção de identidade pessoal mais pretensiosa que a de Locke. Isso porque ela pretende estender, para além das intuições sobre continuidade psicológica, outros elementos metafísicos na caracterização da identidade. O que nos interessa, todavia, será sua discussão com Christine Korsgaard em que serão apontados os limites da posição de Korsgaard, em especial quanto à falta de uma base metafísica para o conceito de pessoa. 


\title{
1 UNIDADE FORENSE E SELFMORAL
}

Para entender melhor essa discussão cabe uma análise do conceito de pessoa como unidade forense ${ }^{2}$. No já citado capítulo 27 do livro II do Ensaio sobre o Entendimento Humano, Locke afirma:

\begin{abstract}
Pessoa, como o entendo, é o nome para esse eu [self]. Onde quer que um homem encontre o que chama de si mesmo [himself], penso que aí outro homem pode dizer que se encontra a mesma pessoa. É um termo forense que associa as ações e seus méritos e, assim, pertence somente a agentes inteligentes capazes de lei, felicidade e miséria (LOCKE, 2015, p. 186).
\end{abstract}

Locke circunscreve a investigação da identidade pessoal a algo identificável em termos práticos, de imputação. Seria possível imputar responsabilidade de um crime a uma pessoa no tempo $\mathrm{Y}$, posterior ao ato criminoso, desde que esta estivesse em conexão psicológica com a pessoa no tempo X, quando o ato foi cometido. Do mesmo modo, é possível gratificar a pessoa no tempo Y, por algo que ela realizou no tempo $\mathrm{X}$, desde que seguido o mesmo critério. Um exemplo famoso utilizado por Locke vem a calhar. Caso todo o conteúdo psicológico de um príncipe seja transferido para o corpo de um sapateiro, é possível dizer que o príncipe agora está no corpo do sapateiro. Se antes de tal transferência o príncipe houvesse cometido um crime, deveria agora receber punição no corpo do sapateiro. Como o que importa para a caracterização da pessoa é o fluxo de consciência, ou a conexão psicológica, faz todo o sentido pensar que o alvo de imputação é o corpo no qual está o conteúdo mental do príncipe.

A unidade forense é importante para a discussão a ser realizada, uma vez que é o conceito básico a partir do qual todas as questões valorativas subsequentes serão feitas. Questões morais, práticas, jurídicas, afetivas e sociais têm como o locus essa unidade básica de atribuição. Schechtman analisa duas formas possíveis de se conceber o conceito de unidade forense. Uma forma é pensá-lo como delimitando o alvo das questões sobre responsabilidade e autointeresse. É possível também pensar a unidade forense por meio do conceito de pessoa como um self moral, ou seja, como um alvo de questões substancialmente normativas.

Um exemplo discutido por Schechtman (2014, p. 14) torna mais claro o que está em jogo nessa diferenciação. Imagine uma mãe que chega ao quarto em que estão seus filhos - Dick, Jane e Spot - e vê uma lâmpada quebrada. Para saber se ela deve punir um dos filhos por ter quebrado a lâmpada dois passos são necessários. Inicialmente, há que se perguntar e identificar quem foi o responsável pelo evento da quebra da lâmpada (imagine que, nesse caso, foi Jane) e, em um segundo momento, há que se investigar as condições do evento para poder extrair conclusões mais robustas em termos morais (se Jane tropeçou e esbarrou na lâmpada é uma coisa, se ela jogou a bola na lâmpada é outra, por exemplo).

Assume-se, em geral, que há dois momentos distintos para eventos de atribuição. O primeiro é o de localização do alvo de atribuição de

\footnotetext{
${ }^{2}$ No original se diz termo forense (forensic term), mas para os presentes propósitos cabe tratar o termo como Schechtman o utiliza.
} 
responsabilidade. Se quem quebrou a lâmpada foi Jane, Dick e Spot devem estar excluídos de saída de qualquer investigação sobre o incidente (pelo menos, na qualidade de suspeitos). Jane é, pois, o locus de imputação da referida ação. O segundo momento, este mais robusto, é aquele em que se pergunta pelas circunstâncias que levaram Jane a quebrar a lâmpada, suas motivações, grau de consciência do que fez, ou seja, o grau de sua responsabilidade moral sobre o fato. (Talvez se Jane apenas por azar quebrou a lâmpada não caiba qualquer sanção). Contudo, será Jane, e não um de seus irmãos, o alvo da possível sanção ou reprimenda.

O objetivo de Schechtman é diferenciar, inicialmente, dois possíveis modos de se pensar a identidade pessoal. Trata-se (i) de um modelo chamado de 'coincidente', no qual unidade forense e self moral possuem os mesmos limites e (ii) de um modelo chamado 'dependente', no qual self moral e unidade forense estão fortemente ligados, mas não são a mesma coisa, podendo, em determinadas situações, ter limites distintos (esse é o modelo de Schechtman). No caso de Jane, por exemplo, pode-se dizer que não faria sentido puni-la caso ela estivesse sob efeito de um medicamento que lhe alterasse a consciência, mas a pergunta "quem devo investigar sobre o incidente da lâmpada?" continua tendo como resposta: Jane. Schechtman afirma que o modelo de coincidência não dá conta de responder a essa intuição expressa no caso de Jane ${ }^{3}$.

Há, contudo, um terceiro modelo que pode ser invocado para explicar a relação entre unidade forense e self moral: o modelo que Schechtman chama de forte independência. Trata-se não apenas de negar uma identificação estrita entre os limites da unidade forense e do self moral, mas de advogar uma independência entre tais âmbitos. As preocupações morais deveriam, segundo essa visão, ser vistas de outro ponto de vista, fazendo com que a caracterização do locus forense seja dispensável para pensar as implicações práticas do conceito de identidade pessoal. Christine Korsgaard seria uma representante desse modelo e o principal artigo no qual ela desenvolve tal visão é Personal Identity and the Unity of Agency: A Kantian Response to Parfit. Nele, a autora defende que a melhor forma de tratar a questão da identidade pessoal é partir do ponto de vista prático e, ao responder a Parfit, que ela situa na tradição humiana e utilitarista, oferece uma visão que remonta ao modo kantiano de se pensar a moral.

\section{KorsgaArd versus PARFIt}

Derek Parfit, em Reasons and Persons, defende uma descrição redutivista de identidade pessoal, ou seja, para ele: "[...] a existência de cada pessoa envolve a existência de um cérebro e corpo, a realização de certos atos, o pensamento de certas coisas, a ocorrência de certas experiências e assim por diante." (PARFIT, 1984, p. 189). Pessoa nada mais é do que o nome dado a um determinado conjunto

\footnotetext{
${ }^{3}$ O primeiro capítulo de Staying Alive se dedica a explicar detalhadamente todas as vantagens de se assumir o modelo de dependência ao invés do modelo de coincidência. Uma vez que interessa para o presente trabalho uma segunda diferenciação, como se verá a seguir, o exemplo de Jane é suficiente para expressar a intuição assumida pela autora.
} 
dessas experiências. Mas quais seriam essas experiências? Como é possível pensálas como constituindo a pessoalidade de modo a tornar coerente o nosso senso comum sobre o que é ser uma pessoa?

A resposta para essa questão passa pela intuição óbvia de que essas experiências, sejam elas quais forem, tenham elas qual peso tiverem, têm que estar, de alguma maneira, relacionadas. A ideia de conexão psicológica e Relação R surge de forma a explicar como uma série de eventos constitui aquilo que chamamos de pessoa. A tese de conexão psicológica já aparece em Locke e seus herdeiros Parfit, com certeza um dos maiores - são conhecidos como 'teóricos da conexão psicológica'. Sobre Locke, o que cabe ressaltar agora é apenas a importância das experiências, mais do que do corpo no qual elas são instanciadas, para a caracterização da pessoa.

Em Korsgaard é possível encontrar uma explicação bem clara do que Parfit tem em mente ao ressaltar a importância da Relação R. Cabe reproduzi-la:

Existe uma conexão psicológica quando, em um dado momento, um estado psicológico está causalmente relacionado de uma forma apropriada com um estado psicológico em um momento anterior. Por exemplo, se Marilyn lembra algo porque Norma Jean experimentou, se Marilyn faz algo porque Norma Jean pretendia, se Marilyn acredita em algo porque Norma Jean foi ensinada, então Marilyn e Norma Jean estão psicologicamente conectadas. Se houver muitas dessas conexões, elas estão fortemente conectadas, e se há cadeias sobrepostas de forte conexão, então Marilyn é psicologicamente contínua com Norma Jean. Neste caso, o que Parfit chama de "Relação-R" - conexão psicológica e continuidade - se mantém entre Marilyn e Norma Jean. Em circunstâncias normais, isso significa que Marilyn é Norma Jean em uma data posterior (KORSGAARD, 1996, p. 365-366).

É importante destacar dois elementos da citação acima: (i) é preciso haver uma relação causal entre os eventos que compõem a Relação R. A lembrança, assim como a crença e demais estados psicológicos, tem que ser causada por uma experiência tipicamente relacionada; (ii) são necessárias várias conexões, muitas delas sobrepostas. Isso é um fator importante, uma vez que é possível partilhar certas conexões de forma fraca e, em menor número, com outras pessoas, seja por confusão de memória ou processos alucinatórios (eu me lembro de algo, mas porque um amigo vivenciou e estou confuso ou alucinando). Apenas uma quantidade razoável de conexões relacionadas conta para se caracterizar determinada pessoa. Uma vez que a Relação R cumpre o papel explicativo e é algo que fornece conteúdo para a caracterização do que é ser pessoa, Parfit afirma que é fundamentalmente a Relação R que importa. Isso quer dizer que, ao sustentar uma tese redutivista sobre a pessoalidade, o foco das discussões deve estar nas conexões relacionadas de uma maneira apropriada.

A proposta redutivista de Parfit não nega que se possa usar o termo pessoa, apenas discorda da ideia que pessoa seja uma entidade que existe independentemente de certas experiências relacionadas em determinado corpo. Ele não vê problema em chamar de pessoa um sujeito de experiências (PARFIT, 1984, p. 223). Tal visão, não obstante, leva a uma consequência que servirá de 
gancho para a crítica de Korsgaard. A visão de Parfit acaba fornecendo poucas razões para que alguém se preocupe com o sujeito de experiências que ocupará seu corpo no futuro. Parece intuitivo que é racional se preocupar com coisas como aposentadoria, planos de saúde, cuidados com o corpo, tendo em vista o futuro. Todavia, em uma visão parfitiana, na qual as relações e conexões com tal sujeito no futuro possam ser muito poucas (principalmente caso a pessoa seja acometida por algum tipo de demência, como Alzheimer), a preocupação com o futuro não seria capaz de se sobrepor a quase nada ${ }^{4}$.

Essa apresentação básica de alguns dos elementos da teoria de Korsgaard e Parfit permite perceber porque Schechtman o enquadra entre aqueles que defendem um modelo coincidente entre a unidade forense e self moral. A preocupação com o sujeito de experiência que ocupa determinado corpo não se estende para além de determinadas relações apropriadas e de certa continuidade psicológica que pode ou não se conservar durante o tempo.

Em Christine Korsgaard, pode-se perceber um modelo que prescinde fortemente de uma relação estrutural entre a metafísica da pessoalidade e o concernimento moral. Ela nega qualquer comprometimento metafísico disponível no debate, e não busca, em um primeiro momento, formular algum. Caso sua explicação faça sentido, a discussão sobre os compromissos da identidade metafísica pode ser deixada em aberto.

Korsgaard trabalha com a divisão kantiana clássica entre ponto de vista teórico e ponto de vista prático. Para ela, o conceito de identidade pessoal é, sobretudo, um conceito prático. Assim, ela acusa Parfit e todos aqueles teóricos do modelo coincidente, de fazer uma passagem não permitida do 'é' para o 'deve', da descrição para a prescrição. Ou seja, de fatos metafísicos acerca da caracterização da unidade forense não se pode tirar, sem mais, qualquer consequência normativa substantiva. Uma vez que o problema de caracterização da pessoalidade é, na visão de Korsgaard, muito mais uma questão prática do que metafísica, o que se deve buscar é uma identidade prática.

Korsgaard constrói seu argumento partindo da intuição de que devemos nos preocupar com o agente racional que ocupará nosso corpo no futuro, mas afirma que não precisa de comprometimentos metafísicos, mas práticos, para fazer tal afirmação. A diferença já se dá inicialmente no uso do vocabulário. Enquanto Parfit utiliza-se da expressão sujeito de experiências, Korsgaard utiliza a expressão agente racional. Essa distinção marca a diferença entre uma posição passiva, na qual todas as experiências possuem o mesmo grau de importância para a

\footnotetext{
${ }^{4}$ Parfit afirma que a preocupação com o futuro não se daria do ponto de vista racional. Para ele realmente não seria irracional não se preocupar com tal sujeito de experiências que ocupará meu corpo no futuro. Contudo, isso seria algo imoral, uma vez que se estaria, de algum modo, fazendo mal a outra pessoa. Assim como parece ser imoral fazer com que a pessoa ao lado inale a fumaça de seu cigarro, seria imoral fazer isso com o sujeito de experiências que estará futuramente no seu corpo e sofrerá as consequências de seu comportamento (1984, p. 321). Não cabe aqui analisar o quão plausível uma resposta dessas seria, mas apenas sinalizar que a via buscada por Korsgaard passa por outro caminho.
} 
caracterização da pessoalidade, e uma posição ativa, na qual a capacidade de ação (agency) é mais fundamental.

A proposta de Korsgaard parte da constatação de que - independente dos muitos 'subsistemas' a operar na vida mental de alguém (desejos, crenças, medos, hábitos) que, em geral, são contraditórios - em algum momento há de existir uma coordenação entre eles. Esse é o momento da ação. Sem coordenação, e aqui o melhor termo seria unificação, a ação é impossível. Se um sujeito quer um corpo magro e ao mesmo tempo viver uma vida de intensos prazeres açucarados, ele terá que, em algum momento seguir uma direção para realizar seus projetos. Deverá agir em prol da realização de algum caminho e abandonar o outro, ou ficará patologicamente paralisado. A ação à qual Korsgaard se refere é uma ação racional na qual são expressos valores e um modo de ser que o agente quer ver realizado no mundo. A imagem do sujeito indeciso entre a vida magra e a vida ultra doce ajuda a ilustrar a necessidade de se coordenar, mesmo que minimamente, os esforços pessoais para agir (ainda que junto à ação estejam sentimentos internos de grande indecisão). A necessidade de agir é, contudo, um dado bruto, cru da realidade e isso conta favoravelmente à tese da autora.

Um segundo argumento apresentado em prol da tese da necessidade de unificação mostra que, para seres como nós, não basta agir, mas é preciso que a ação seja expressiva do modo como nós nos vemos. Em outras palavras, é preciso que o agente se veja como o autor daquelas ações e não como um 'simples' sujeito de experiências.

O ponto de vista disponível ao agente é, então, prático. Destaca-se aqui a necessidade do caráter autônomo da ação. Autonomia é uma noção cara aos kantianos e Korsgaard expressa isso de forma muito clara ao afirmar que "Identificar-se com um princípio ou forma de escolher é dar uma 'lei a si mesmo' e ser unificado como tal." (KORSGAARD, 1996. p. 370). Percebe-se aí o caráter exigente da proposta e do modo como a autora concebe a ação resultante do processo de unificação que está envolvido na experiência pessoal de um agente racional.

Essa explicação torna mais clara a tese de que há certa independência entre o ponto de vista teórico e o prático. O primeiro visa explicar as ações sob o ponto de vista de forças causais e 'subsistemas' funcionando em disputa. É possível olhar desse ponto de vista, mas isso parece realmente não responder às questões envolvidas no debate sobre a caracterização da pessoalidade. "É a razão prática que me obriga a construir uma identidade para mim; se a metafísica me orienta sobre isso ou não é uma questão aberta." (KORSGAARD, 1996, p. 371). O fato de deixar a questão em aberto permite à autora ao mesmo tempo não ter que discordar da noção redutivista de Parfit (ou apresentar argumentos prós e contra ela, embora em vários momentos ela concorde com a ideia de que não é preciso postular entidades extras para definir a pessoalidade), mas dizer que o foco do debate está no lugar errado e, por isso, não é capaz de resolver a questão.

Tendo isso em vista, é possível retornar ao ponto a partir do qual é iniciada a argumentação de Korsgaard: a racionalidade ou não da preocupação com o 
futuro. A autora tem um ponto importante quando afirma que, quando se foca na ideia de pessoa como agente racional, como um ser autônomo e que é capaz de dar uma lei a si mesmo, não faz sentido pensar a pessoalidade de forma restrita ao tempo presente. Isso porque para que a unificação possa ocorrer - para que a pessoa seja o que é, no presente - ela precisa ser um agente de valores que expressem um modo de ser que só é realizável ao longo de um tempo. Pretensões, planos e valores que nos conectam com o futuro são necessários para a construção da nossa atual identidade.

Imagine um aluno que ingressa na pós-graduação por se identificar com a carreira acadêmica. Para que ele possa se unificar como um agente racional no instante atual, os seus projetos de vida já devem estar presentes em sua mente. Tais projetos contam para as ações que ele tomará cotidianamente. Por isso, entre postergar o trabalho final de uma disciplina e se dedicar um pouco mais até o fim do dia, ele tenderá a escolher a segunda opção. E, uma vez que se trata de uma identidade prática, as escolhas são a expressão de um modo típico de ser que ele vê como valorativo. O mesmo ocorre com uma pessoa que é preocupada com sua saúde e se alimenta de forma balanceada uma vez que entende que conservar uma vida saudável é um valor a ser vivido. Tal pessoa tem em vista um projeto a ser realizado e a escolha entre coca cola e água com rodelas de pepino tenderá à última opção, por mais implausível que isso possa parecer, principalmente a alguém que se detiver apenas ao tempo presente.

Isso leva a outro ponto interessante da argumentação da autora: nessa forma de pensar a pessoalidade, alguns conteúdos mentais possuem maior importância que outros. Em especial as conexões psicológicas tidas como autorais, se sobrepõem às outras. A ideia de uma conexão psicológica autoral está diretamente ligada à noção de ponto de vista prático, no qual, pessoas veem suas ações de um modo essencialmente próprio. Mais do que um conjunto de desejos pró e contra, creio que eu sou aquele que escolho escrever o artigo e não assistir uma série. Eu sou escolhedor, sou o autor das minhas ações.

Tendo isso em vista é possível dizer que certas conexões psicológicas não racionalmente endossadas, que fazem parte de nosso conteúdo mental apenas de modo acessório, não possuem a mesma importância que outras criticamente pesadas. É uma conexão forte, no sentido autoral, aquela que liga o atual professor ao aluno de pós-graduação que se esforçou para entrar na academia. No caso da pessoa de vida saudável, as conexões ligadas às escolhas alimentares e físicas que a constituem são mais fortes do que possíveis gostos secundários ou lembranças de momentos em que ela não seguiu a sua dieta por um motivo qualquer.

Nunca é demais lembrar a verve kantiana de Christine Korsgaard, que faz com que as exigências de endosso racional a determinadas práticas sejam muito maiores do que em outros autores. Não basta uma ação qualquer, não examinada, fruto das pulsões. Para que uma ação seja considerada minha é preciso que eu seja capaz de endossá-la racionalmente e assumi-la como expressiva da minha personalidade. São essas as verdadeiras ações autônomas do agente racional e aquelas que contam para a constituição da identidade prática. "Isso porque crenças 
e desejos aos quais você chegou ativamente são mais verdadeiramente seus do que aqueles que simplesmente chegaram a você." (KORSGAARD, 1996, p. 379).

A importância do endosso racional permite explicar como grandes mudanças não implicam perda de identidade desde que sejam autonomamente executadas. Korsgaard lembra que, em geral, experiências de pensamento envolvendo mudança de personalidade se valem de algum tipo de atuação externa (como cirurgiões manipulando o cérebro, transplantando memórias etc). Contudo, uma vez que o motor da mudança seja interno e a motivação racional, o tamanho da mudança (seja ela uma conversão mística, ideológica etc.) parece não acarretar perda da identidade. Esses fatores mostram a importância da ação para constituição da identidade no modelo de Korsgaard.

\section{A CRÍtICA DE SCHECHIMAN}

Schechtman, no capítulo dois de Staying Alive, reconstrói a posição de Korsgaard e a situa no modelo de forte independência entre unidade forense e self moral. Nessa leitura, Korsgaard afirma que se pode tratar das questões de responsabilidade moral sem qualquer referência a uma unidade de atribuição, ou seja, independente da unidade forense. Todo o esforço de Schechtman será no intuito de tentar mostrar que tal empreitada está fadada ao fracasso, ou seja, que seria impossível tratar questões práticas sem o recurso a uma unidade mais básica.

A crítica é sobre o destacado papel que certas ações autônomas e racionalmente endossadas possuem na constituição da pessoalidade, na visão de Korsgaard. O argumento de Schechtman é que, para essas ações emergirem como constituintes da pessoalidade, é preciso que elas estejam em relação com outros conteúdos mentais não endossados, mais fracos etc. E que, por conseguinte, é preciso certo locus que delimite quais são esses meus conteúdos. Logo de início Schechtman dá um exemplo que ilustra isso: se Kate está com raiva e eu calmo, é Kate que tem que decidir se endossa sua raiva entre os vários possíveis estados emocionais disponíveis.

Como delimitar esse locus? É possível imaginar o caso de Kate, uma moça que após um tempo na prisão decide deixar para trás todas as suas mágoas e problemas do passado e seguir uma nova vida. Ela segue um plano de mudança que inclui terapia, trabalho voluntário etc. Tudo isso está contemplado no modelo de Korsgaard. Ela autonomamente decide endossar uma identidade prática, seus planos futuros constituem a sua identidade atual etc. Em um caso de transferência de cérebro ${ }^{5}$, no qual seu cérebro é transplantado para o corpo de Juliet, parece agora que é o amálgama KJ (conteúdo mental de Kate e corpo de Juliet) que terá que coordenar os planos futuros de Kate. Será KJ que decidirá se continua a terapia, o trabalho voluntário e outras atividades. Korsgaard concordaria com isso e realmente parece ser a resposta mais intuitiva à questão. A questão que

\footnotetext{
${ }^{5}$ Cérebro aqui cumpre a função de indicar 'conteúdo mental' (se conteúdos mentais estão abrigados em unidades orgânicas mais amplas e mais complexas [tais como o sistema nervoso central], então falaremos nelas e não apenas no cérebro.
} 
Schechtman coloca é, então, por quê? A resposta, para ela, parece óbvia, porque o conteúdo psicológico de Kate está nesse novo corpo.

O ponto central dessa ilustração é mostrar que uma certa unidade, ou que pelo menos um estabelecimento de limites, parece ser necessário para o estabelecimento da ideia de pessoalidade. Há uma crítica tácita à preponderância de certos conteúdos mentais, como se apenas aqueles racionalmente endossados, aqueles chamados anteriormente de autorais, fizessem parte da identidade. Schechtman diz que, para que esses apareçam como salientes, eles precisam estar em relação, superando outros conteúdos em conflito. E para dizer quais conteúdos contam é preciso, de saída, ter uma teoria sobre uma unidade básica, chamemo-la de unidade forense ou não.

Antes eu disse que é pressuposto na visão de Korsgaard que há algum conjunto de impulsos e motivações que eu devo coordenar se eu espero me constituir como um agente. Reflexões sobre a coordenação diacrônica no caso de transferência de cérebros ajuda a destacar o fato de que o que delimita quais são esses impulsos e motivações é algo como as relações que, de acordo com os teóricos da continuidade psicológica, definem a identidade pessoal. É porque K.J experimentará o mesmo conjunto de impulsos conflitantes que Kate experimentou que é dela o futuro corpo com o qual Kate deve tentar coordenar a ação. É porque ela tem a vida psicológica de Kate - não apenas a parte que ela endossa, mas também a parte que ela repudia - que K.J é a pessoa que, no caso relevante, completa ou falha em completar o plano de vida que Kate começou (SCHECHTMAN, 2014, p. 59).

Schechtman reconhece, pois, a tentativa de se construir uma explicação que não se comprometa com algo como o que querem os teóricos da conexão psicológica. Korsgaard parece querer evitar a ideia de que é necessário um sujeito metafísico para a base da pessoa. Prefere dizer que a coordenação das ações é feita conscientemente - um modo distinto de compreendê-las sem anterioridade metafísica. Não haveria, em outras palavras, uma unidade anterior consciente, mas uma unificação consciente na ação. O que é primário nesse caso são as ações, o caráter prático, mais do que o caráter metafísico, uma vez que Korsgaard defende que o conceito de pessoa é um conceito prático. Ela, desse modo, não ignoraria os conteúdos mentais assumidos pelos teóricos lockeanos, mas afirmaria que só podem ser entendidos como relacionados à formação da identidade pessoal, se vistos do ponto de vista prático.

$\mathrm{Na}$ visão de Schechtman, o que Korsgaard consegue realizar é a crítica a uma unidade básica constituída por um sujeito consciente unificado, postulada pela tradição da conexão psicológica. Antes da ação não há tal coisa e não é possível compreender a pessoalidade sob esse ponto de vista. Já a recusa total de certa base na qual estão contidos diversos conteúdos mentais relacionados, mas ainda não articulados racionalmente, parece não ser possível. Schechtman resume assim seu ponto: 
A visão de Korsgaard envolve assim dois tipos importantes, e significativamente distintos, de unidade para o entendimento da base da responsabilidade moral. Primeiro, há um conjunto variado de impulsos e motivações que eu estou em posição de coordenar e integrar e que devem ser coordenados e integrados antes que eu possa tomar uma ação autônoma; e há um subconjunto de tais impulsos e motivações que eu endossei e dei autoridade para representar-me na ação. É por essa razão que eu afirmo que a visão de Korsgaard inclui algo como uma unidade forense, cuja identidade deve ser pressuposta para dar sentido às nossas práticas forenses (SCHECHTMAN, 2014, p. 61).

O objetivo da crítica parece ser levar Korsgaard a se comprometer metafisicamente e oferecer alguma resposta à questão. Schechtman quer mostrar que um modelo de forte independência não dá conta de entregar as respostas necessárias para a caracterização da pessoalidade. A opção lockeana, ao menos a visão tradicional assumida por Parfit, não é opção para ambas, mas enquanto Korsgaard é lida como caminhando para um modelo de forte independência, Schechtman defenderá um modelo de dependência, no qual a delimitação do self moral necessita de uma unidade forense de fundo, embora não seja com ela coincidente.

\section{SOBRE EXIGÊNCIA E INDEPENDÊNCIA FORIE}

As críticas de Schechtman a Korsgaard parecem ter como principais dois conteúdos: o primeiro tem a ver com o critério extremamente exigente para que ações sejam tomadas como constituintes da identidade prática; o segundo tem a ver com a ideia de que há realmente uma independência forte entre questões metafísicas e práticas no modelo de unificação da ação.

Sobre o primeiro conteúdo da crítica, parece haver realmente certo exagero quanto à definição do que faz uma ação ser constituinte da identidade prática. Korsgaard se detém fortemente nas conexões psicológicas autorais. O caráter racionalmente endossado de tais conexões exige um passo atrás na ação, que os princípios sejam ponderados, as consequências, opções alternativas, etc. O problema é que tais exigências, se não praticamente inviabilizam boa parte de nossas ações, as faz, ao menos, muito difíceis de serem tomadas. A consequência disso é que teríamos que admitir que grande parte de nossas ações não são nossas, no sentido que Korsgaard gostaria. A vida cotidiana é, em geral, não examinada e, ao não ser em ocasiões específicas de dilemas, as ações por meio de razões conscientemente endossadas ao modo kantiano não são comuns. Desse modo, o primeiro conteúdo da crítica de Schechtman ecoa aquilo que normalmente é levantado contra os seguidores de Kant e há bastante razoabilidade em se apontar essa dificuldade no que tange à excessiva exigência requerida por eles.

O segundo conteúdo da crítica é mais complicado de analisar e talvez outra visão da posição de Korsgaard possa suavizá-lo. Schechtman afirma que o modelo de Korsgaard é de forte independência. Isso porque, a identidade prática poderia ser pensada de modo totalmente independente de uma unidade forense. A crítica 
é que isso não é possível: algum tipo de unidade - mesmo que não a dos lockeanos, de um sujeito consciente - é necessário. Talvez seja possível ler o modelo em questão não como de forte independência, num sentido radical (de que não é preciso uma base metafísica), mas sim que o ponto de vista prático é distinto e, de certo modo, autônomo.

Lembremos que Korsgaard afirma: "É a razão prática que me obriga a construir uma identidade para mim; se a metafísica me orienta sobre isso ou não é uma questão aberta." (KORSGAARD, 1996, p. 371). Sua tese parece ser mais suave do que à primeira vista o rótulo de forte independência parece mostrar. O que está em jogo é que este ou aquele modo de identificar o substrato metafísico não é fundamental para pensar o conceito prático em questão. Talvez seja esse o caso quando Korsgaard compara a ideia de pessoa à figura do Estado. Ela afirma que o Estado é "uma entidade formal e moral, definida por sua constituição e procedimentos deliberativos" (KORSGAARD, 1996, p. 373). Mais intuitivo ainda é uma figura que nosso corpo jurídico reconhece que é a 'pessoa jurídica', ou seja, também uma entidade formal, com regras e procedimentos. O que parece estar em jogo é que há em algum momento a necessidade se coordenar as ações e se unificar para isso. O que vai compor a base é aquilo que estará envolvido na coordenação.

O caso de Kate, citado anteriormente, ajuda a pensar. Se Kate sente raiva, do ponto de vista da ação pessoal, é ela quem tem que coordenar seus impulsos e não eu, porque é ela quem vai se unificar para agir, não eu. Caso tivéssemos sempre que agir em conjunto, a raiva dela seria um problema meu também, teríamos que nos unificar como agentes. O fato do locus da ação ser um corpo biológico é algo contingente. É a nossa constituição que faz com que as partes envolvidas no processo de identificação estejam confinadas em um corpo singular. Mas não é isso que importa, no fim das contas, para a discussão (ao menos no como como é pensada por Korsgaard).

Quando um grupo de seres humanos ocupa o mesmo território, por exemplo, eles têm uma necessidade imperativa de formar um Estado unificado. E quando um grupo de funções psicológicas ocupa o mesmo corpo humano, elas têm uma necessidade ainda mais imperativa de se tornar uma pessoa unificada. É por isso que o corpo humano deve ser concebido como um agente unificado. Sendo as coisas como são, esse é o tipo básico de agente. Claro que se nossa tecnologia fosse diferente, corpos humanos individuais poderiam não ser o tipo básico de agente. Meu argumento sustenta um critério físico de identidade, mas somente um critério condicional. Dada a tecnologia que nós temos agora, a unidade de ação é um corpo humano. (KORSGAARD, 1996, p. 373, grifo da autora).

Dizer que o modelo de Korsgaard é independente tem que ser lido à luz desse tipo de independência, algo que dista de uma primeira leitura do modo como a crítica é construída. Certamente há uma independência se a dependência for aquela que Schechtman postulará na continuação de sua obra, qual seja, a dependência de uma unidade forense delimitada em sentido muito próprio, como o nosso corpo atual em suas dimensões biológicas, culturais e sociais. Schechtman 
defende uma metafísica mais robusta da pessoalidade entendida como aquela instância que ocupa um lugar num espaço constituído por uma série de fatores já dados. Korsgaard não pretende se comprometer com esse tipo de afirmação, deixando sua teoria mais aberta a diferentes modos de constituição, focando mais fortemente no caráter prático necessário à ação. Caso sejam suavizadas as exigências kantianas dessa ação, as credenciais desse tipo de modelo parecem ser adequadas e capazes de fornecer uma boa imagem da caracterização da pessoalidade.

Cabe notar, por fim, que Korsgaard parece ser muito cuidadosa ao não estender o termo pessoa quando dá outro tipo de exemplo de agente unificado que não aquele constituído por um corpo humano biológico. Talvez, assim como Parfit (que afirma que o que importa é a Relação-R) ela possa dizer que, no fundo, é o agente que importa. Isso a levaria a resguardar o termo pessoa ao uso comum do vocábulo, como vinculado diretamente a seres como nós, num sentido que Schechtman poderia concordar. Mas para isso Korsgaard teria que ter um argumento auxiliar, que ela não apresenta, ao menos no artigo aqui em debate. Nele, ela parece apenas tomar o cuidado de construir sua teoria toda sobre a ideia de agente, mais do que de pessoa, deixando aberto se os termos são ou não intercambiáveis.

\section{CONSIDERAÇÕES FINAIS}

O debate sobre identidade pessoal possui uma série de nuances e problemas que se interconectam, fazendo com que tratar do tema seja sempre uma missão espinhosa. Este trabalho apresentou e discutiu uma questão específica sobre a caracterização da pessoalidade, ou seja, sobre o que é ser pessoa. Abordou também, de maneira acessória, questões como a permanência da identidade no tempo.

O recurso a Locke, no início do texto, se deu no intuito de caracterizar o problema a ser discutido. É já em seu texto que pessoa é considerada um termo forense e a questão da caracterização de pessoa como uma unidade básica se coloca. Parfit representa a leitura contemporânea de um tipo de visão que compreende em termos lockeanos a coincidência entre uma unidade forense, em termos de simples atribuição, e self moral.

Uma vez que, principalmente em Locke, as questões coincidem, um tratamento filosófico da distinção aparece em Marya Schechtman. É ela quem, para preparar a sua tese sobre pessoalidade, assinala as diferenças entre a unidade forense e self moral. O ponto do argumento é, como dito no texto, separar o passo inicial de caracterização da unidade forense, de um passo posterior que são os resultados dos julgamentos morais substantivos feitos a essa unidade.

Schechtman acerta ao fazer essa diferenciação e também parece ter razão ao defender algo como uma relação entre as duas coisas. A apresentação da tese de Korsgaard se deu, não no intuito de colapsar a distinção, mas como modo de assinalar que é possível trabalhar a questão não em termos tão metafisicamente 
carregados, mas com certa independência entre os domínios, como o artigo buscou defender. Se as conclusões da última parte do artigo forem aceitáveis, há uma relação entre os dois domínios (unidade forense e self moral), mas essa relação é de independência substantiva, ou seja, de independência em relação a esta ou aquela unidade, não de independência a qualquer unidade.

A posição de Korsgaard possui boas vantagens, em especial por compreender que a questão relevante para todo o debate é uma questão prática, mais do que metafísica. Com isso ela consegue esvaziar o problema metafísico (mas não excluí-lo) e não se comprometer com essa ou aquela explicação. Se a leitura apresentada nesse artigo estiver correta, Korsgaard tem elementos disponíveis para responder à crítica substantiva de Schechtman e a tese da identidade pessoal como identidade prática parece mais robusta e capaz de fornecer uma boa resposta ao debate sobre a caracterização do que é ser uma pessoa.

\section{REFERÊNCIAS}

KORSGAARD, C. M. Personal identity and the unity of agency: A Kantian response to Parfit. In: Creating the Kingdom of Ends. Cambridge: Cambridge University Press, 1996.

LOCKE, J. Ensaio sobre o Entendimento Humano - Livro II.27. Da identidade e da diversidade. Tradução de Flávio Fontenelle Loque. Sképsis, n. 12, 2015.

PARFIT, D. A. Reasons and Persons. Oxford: Oxford University Press, 1984.

SCHECHTMAN, M. Staying Alive. Oxford: Oxford University Press, 2014.

Recebido em: 29-05-2019

Aceito para publicação em: 12-06-20 